This is the penultimate draft of a paper for Epistemic Autonomy which is being edited by J. Matheson and K. Lougheed, and coming out with Routledge

\title{
Persuasion and Intellectual Autonomy
}

Robin McKenna

University of Liverpool

\section{Introduction}

In "Democracy, Public Policy, and Lay Assessments of Scientific Testimony" Elizabeth Anderson (2011) identifies a tension in contemporary democratic societies between the requirements of responsible public policy making and democratic legitimacy. Responsible public policy making in a technologically advanced society should be based on the available scientific evidence. But, to be democratically legitimate, there must be broad (though not universal) acceptance of the policies which are put in place. This, in turn, requires broad acceptance of the science on which these policies are based. But there are many public policy issues where sizeable minorities reject the science on which responsible public policy making might be based. Consider climate change. In many countries, particularly the US, a sizeable minority rejects the science on climate change (Ballew et al. 2019; Tranter and Booth 2015). Further, this minority tend to hold similar political views (pro-free market and anti-regulation). Once politics and science become intermingled in this way, the prospects of broad consensus emerging seem dim, given the difficulty of persuading people to change their minds about things they regard as integral to their political identities.

In this chapter I consider this tension (henceforth "Anderson's tension"). ${ }^{1}$ My first aim is to show that the tension is harder to resolve than Anderson supposes because not all ways of securing public acceptance of the science on which public policy making is (or might be) based are themselves democratically legitimate. ${ }^{2} \mathrm{My}$ second aim is to address the worry that what we can call "science marketing" methods are problematic from a democratic perspective because they infringe on

\footnotetext{
${ }^{1}$ Anderson is not the first person to note the tension (it is central to Kitcher 2001), but she addresses it in the same way I do here-from the perspective of an applied social epistemology.

${ }^{2}$ Anderson's own solution to the tension seems to ignore this. She proposes what she calls in Anderson (2006) an "institutional epistemology": an epistemology that looks at how social institutions (like science) can do a better job of producing and disseminating knowledge. On the dissemination side, Anderson draws on the empirical literature on science communication that I discuss in $\$ 2$. But she doesn't address whether the methods recommended in this literature are themselves democratically legitimate. As I argue in $\$ 3$, you might think they aren’t because they seem to infringe on our intellectual autonomy.
} 
our capacity to make up our own minds about the issues in question. I argue that, while some sorts of marketing may be problematic, and over-use of any sort of marketing may be problematic, there is no reason to think that judicious use of certain kinds of marketing need infringe on our capacity to make up our own minds. While this may not quite resolve Anderson's tension, it lays some of the necessary groundwork for resolving it.

Here is the plan. In \$2 I review some empirical research on how people can be persuaded to change their minds, with a strong focus on work on climate change and climate change skepticism. The result of this review is that science marketing methods are often more effective than methods of rational persuasion. In $\$ 3$ I discuss why some think that marketing methods are problematic from a democratic perspective. The basic idea is that they are problematic because they infringe on our capacity to make up our own minds - on our intellectual autonomy. In \4-5 I look at two recent papers which argue that nudges (in the sense of Thaler and Sunstein 2008) are problematic because they are incompatible with the development of intellectual autonomy (Meehan 2020; Riley 2017). While nudges aren't quite the same thing as marketing methods, they share many of the same features, and the "science marketing" methods I discuss in \$2-3 are plausibly examples of nudges. I argue that, while Riley and Meehan show that "overenthusiastic" use of nudging or marketing methods may be incompatible with the development of intellectual autonomy, there is no reason to think that more judicious use of such methods is incompatible with the development of intellectual autonomy. I finish in $\$ 6$ by identifying what I take to be the crucial unresolved issue, which is the value of intellectual autonomy itself.

\section{Tackling Climate Change Skepticism}

In this section I survey the empirical literature on how people can be persuaded to change their minds about scientific issues, with a strong focus on how climate change skeptics can be persuaded to change their minds.

Let's start with some figures. $97 \%$ of climate scientists agree that human activity is a major cause of climate change (Cook et al. 2016). Bur a recent study in the US found the following (Ballew et al. 2019):

- Around seven in ten Americans think climate change is happening and around one in eight Americans think climate change is not happening.

- Around six in ten Americans think that climate change is mostly human caused and three in ten think it is due mostly to natural changes in the environment.

- Just over half of Americans realise that most scientists think climate change is happening. But only about one in five realise how strong the level of consensus among scientists is. 
The good news is that seven in ten Americans think climate change is happening. The slightly less good news is that only six in ten think it is mostly human caused. The far less good news is that just over half realise that scientists are almost unanimous. But how good or bad this news is depends on who thinks these things. Views about climate change (whether it is happening, what is causing it, and whether scientists agree about it) correlate strongly with political views. Ballew et al. (2019) found that, while almost all "liberal Democrats" think that climate change is happening (as do most "moderate Democrats"), less than half "conservative Republicans" think climate change is happening. Given the breakdown of opinion above, it is reasonable to suppose that even fewer conservative Republicans think that climate change (if it is happening at all) is mostly human caused, or that most scientists think climate change is happening. In the US climate change therefore poses precisely the problem Anderson identifies. While there is fairly broad acceptance that climate change is happening, there is a sizeable minority, which also happens to be politically powerful, that denies this. The question is: how could we persuade them that they are wrong?

There are lots of things you might try. You might think the problem is a lack of scientific understanding, so the solution is more and better science education, perhaps allied with more emphasis on critical thinking in education (Bak 2001; Sturgis and Allum 2004). But there are two broad reasons to be skeptical about the chances of this strategy succeeding.

First, as we have seen, attitudes about climate change correlate with political views. There are two possible explanations for this. One is that levels of scientific understanding vary with political views, and conservative Republicans understand less about climate science than liberal Democrats. If this were right, we would expect that, among conservative Republicans, the better informed will be more likely to think that climate change is happening, and that (if it is happening) it is mostly human caused. But this prediction is not borne out by the evidence. A 2019 Pew Research Center survey found that, while the percentage of liberal Democrats who think that climate change is mostly human caused increases with level of scientific understanding, conservative Republicans who are more scientifically informed are slightly less likely to think that climate change is mostly human caused (Funk and Kennedy 2019).

An alternative explanation is that our background political views influence how we process information, including information about scientific developments. We are motivated to find ways of understanding the information we receive that enable us to vindicate rather than reject these background views (Hamilton et al. 2015; Hamilton 2011; Hardisty, Johnson, and Weber 2010; Hornsey et al. 2016; Kahan, Jenkins-Smith, and Braman 2011; Lewandowsky and Oberauer 2016; Tranter and Booth 2015). This explanation, which is developed by those who work on 
"politically motivated reasoning", can explain why more knowledgeable conservative Republicans are no more likely to accept the science on climate change. They, like all conservative Republicans, are motivated to preserve their basic conviction that there should be limited (or no) regulation on industry, and to do this they need to reject the science on which policies promoting regulations could be based.

Second, everyone underestimates the extent of scientific consensus on climate change regardless of political affiliations because there is so much misinformation about climate change in the public sphere (Cook 2017; 2016; Cook et al. 2018). While "consensus messaging" (informing the public that scientists agree on an issue) can be a good way of educating the public (Cook and Lewandowsky 2011; Toby Bolsen, Leeper, and Shapiro 2014; Lewandowsky, Gignac, and Vaughan 2013; van der Linden et al. 2014), consensus messaging about climate change clearly hasn't "cut through" with sections of the population. A likely explanation is that the efficacy of consensus messaging is reduced when there is widespread misinformation, including about whether there is a consensus (Cook 2017; 2016; van der Linden et al. 2017). As van der Linden et al. (2017) put it:

Results indicate that the positive influence of the 'consensus message' is largely negated when presented alongside [misinformation]. Thus, in evaluating the efficacy of consensus messaging, scholars should recognize the potent role of misinformation in undermining real-world attempts to convey the scientific consensus (p. 5).

So the problem is not (just) poor understanding of science and lack of critical thinking ability. This may be part of the problem, but both are supplemented by the influence of politically motivated reasoning and the amount of misinformation in the public domain about something like climate change. Because more science education won't necessarily help with either of these things (particularly with tackling the influence of politically motivated reasoning) something else is needed.

What can we do? We can turn to the literature on climate science communication for some possible strategies. I will discuss three strategies. In each case, the strategy is a "marketing method"-it aims to sell a product (climate science) rather than to persuade by (merely) providing relevant information or argumentation.

First, we can consider how the issue is framed. How willing people are to accept particular policies to mitigate the effects of climate change, and even how willing they are to say they accept the underlying science, depends on how things are described (Campbell and Kay 2014; Corner et al. 2015; Dahlstrom 2014; Dryzek and Lo 2015; Hardisty, Johnson, and Weber 2010; Kahan 2014; MacInnis et al. 2015). Compare two different ways of describing the challenge posed by climate change. You might put it in terms of what we can do to reduce carbon emissions. 
Or you might put it in terms of what new technologies we might develop to meet the challenge. Perhaps unsurprisingly, people react differently to these two ways of describing the problem. Describing the problem as a technological problem can make those who are ideologically opposed to any regulations on industry more willing to accept that action is needed to combat climate change (Kahan et al. 2015). Similarly, the term "carbon offsetting" is less off-putting to many than the term "carbon tax" (Hardisty, Johnson, and Weber 2010).

Second, we can consider who the messenger is. Climate scientists have often taken on this role, which makes sense given that public trust in scientists is high (American Academy of Arts \& Sciences 2018; Ipsos MORI 2014). But the evidence suggests that we would be better off if a more diverse (in multiple senses of the word) group of people made a public case for action. Scientists are not the most trusted source on every issue, or necessarily the best people to deliver messages on issues that have become politically contentious (Cvetkovich and Earle 1995; Cvetkovich and Löfstedt 1999; Kahan 2010; Moser and Dilling 2011). Further, our political beliefs influence how we assess expertise in the first place. Put crudely, we would often rather rely on someone we perceive to share our political beliefs and values than someone with different values from our own, no matter how much of an expert they are (Kahan, Jenkins-Smith, and Braman 2011). While this can be a real problem, it has some upsides. It means that ensuring a diverse group of people deliver the message will likely be effective.

Third, we can consider which communicative strategies we use in the first place. It is common to pursue a "debunking" strategy: take some claim made by climate change skeptics and show why the claim is false. While debunking can work, it is often less effective than you might expect because misconceptions and false beliefs can be hard to dislodge (Lewandowsky et al. 2012; Seifert 2002). For this reason, many have considered an alternative strategy which is often called "prebunking". Where debunking is a matter of refuting a belief that has already been accepted, prebunking is a matter of giving people the tools to avoid being taken in by false claims in the first place. While this might not sound so different from the idea that we need to improve critical thinking skills, it is different in that "prebunkers" envisage a more targeted strategy that is based on something called "inoculation theory" (Compton 2013). The thought is that you can inoculate someone against certain forms of misinformation and misleading ways of arguing by exposing them to these forms of misinformation and misleading ways of arguing in controlled environments (Tony Bolsen and Druckman 2015; Cook, Lewandowsky, and Ecker 2017; Ivanov et al. 2015; Pfau 1995; Pfau and Burgoon 1988; van der Linden et al. 2017). For instance, you might present someone with a common climate skeptic argument along with a refutation of it. Take the claim that human $\mathrm{CO}_{2}$ emissions are tiny in magnitude compared to natural emissions. You would accompany a 
presentation of this argument with the refutation: human $\mathrm{CO}_{2}$ emissions interfere with the natural carbon cycle, putting it out of balance.

I have discussed three strategies that we have reason to think might be effective in persuading people to change their minds about climate change. Let me finish by highlighting what they have in common. The idea is that we can use these strategies to construct a better epistemic environment - an environment in which it is easier for people to recognise that they hold false beliefs about an issue like climate change, and to form true beliefs instead. But the crucial thing is that someone who utilises these strategies isn't trying to construct a better epistemic environment just by increasing the amount of knowledge that is "out there" waiting to be discovered. Rather, they are trying to target groups of people with a message or in a way that is designed to produce a certain outcome (they abandon a false belief and adopt a true one). As such, it seems fair to describe these strategies as "marketing methods" - someone utilising them views (climate) science as a product that needs to be sold to a (sometimes) skeptical public.

\section{Marketing and Intellectual Autonomy}

In this section I will explain why some think that marketing methods are problematic. To do this I will draw on a recent paper by Arthur Beckman (2018), "Political Marketing and Intellectual Autonomy", which lays out the reasons why political marketing is viewed with suspicion. I will argue that what Beckman says about political marketing methods also seems to go for the "science marketing" methods discussed in the previous section.

Beckman says that suspicion of political marketing is due to the idea that:

[political] marketing methods diminish the ability of citizens to deliberate autonomously about government policies and processes, questions of government effectiveness, political candidate choices, and social mores, both personally and with others (p. 24).

There are some complications here. Setting aside the question of whether political marketing is effective, you might think it has some benefits (e.g. it provides people with relevant information). But the basic thought is that political marketing is problematic because it interferes with the capacity of citizens to deliberate autonomously. This is not surprising, given the aim of political marketing is to shape public opinion in desired directions. If people deliberate autonomously, then you have little control over what the outcome of their deliberations will be.

But what is autonomous deliberation, and why does Beckman think that political marketing diminishes the ability of people to engage in it? Beckman, in line with the general trend in discussions of intellectual autonomy in epistemology, distinguishes between solitary and autonomous deliberation (cf. Adam Carter 2017, 
Roberts and Wood 2007 and Zagzebski 2013). Your deliberations can be informed by social interactions and the information and diverse perspectives they provide and still be autonomous. So, for Beckman, autonomous deliberation is not solitary deliberation but rather deliberation that is free from certain forms of interference such as deception, misinformation, framing, omission of crucial information, agenda-setting, priming, selective provision of information and distortion of facts. Intellectual autonomy is then a capacity to form opinions (intellectual autonomy) and take actions (something closer to political autonomy) on one's own, without these forms of interference. One can therefore deliberate autonomously, and be intellectually autonomous, while still engaging in extensive social interaction. (You might wonder about the equation of autonomous deliberation with intellectual autonomy - intellectual autonomy is a capacity, whereas autonomous deliberation is an activity. I return to this in $\$ 4-5)$.

Beckman thinks political marketing interferes with autonomous deliberation and intellectual autonomy precisely because it involves a combination of deception, misinformation, framing, omission of crucial information, agenda-setting, priming, selective provision of information, and distortion of facts. The "political marketer" employs methods designed to set political agendas, to frame issues in advantageous ways, to construct and reinforce desired political attitudes and create desired habits of political information processing. Summing up, he says that

Notwithstanding its limitations, political marketing can provide predictable and significant means of establishing, promoting, reinforcing, and altering attitudes, perceptions, decision-making processes, and behavior. These capabilities can constrain the intellectual autonomy of citizens, and have demonstrably narrowed its scope. Rationalization of political information, its transmission, and its processing by way of media and marketing communications produces homogenized political cognition and ready-made political belief systems, attitudes, and identities — all of which may facilitate marketing strategies (p. 40).

Beckman's paper is about political marketing, but his argument can also be applied to the "science marketing" methods I discussed in the previous section. Like political marketing, science marketing employs processes that are designed to produce desired outcomes. Like the political marketer, the "science marketer" wants to shape public opinion. They want to secure acceptance of certain scientific claims and to alter attitudes and perceptions of the relevant issues.

Similarly, a case can be made for thinking that science marketing interferes with autonomous deliberation and intellectual autonomy. We saw that Beckman thinks that political marketing interferes with autonomous deliberation and intellectual autonomy because of the sorts of methods the political marketer employs. They try to frame issues in advantageous ways and to construct and reinforce desired attitudes and ways of processing information. But the science marketer also 
employs methods that are designed to do these things. Of the three strategies discussed in the previous section, the first two (framing and selecting an appropriate messenger) are designed to construct and reinforce certain attitudes and ways of processing information and to frame issues in certain ways. The third strategy (debunking) is also designed to construct certain attitudes and ways of processing information.

In short, it looks like, if political marketing is problematic because it infringes on autonomous deliberation and intellectual autonomy, then science marketing is problematic for the same reason. My aim in the rest of the paper is to go some way towards arguing that science marketing is not problematic (at least for this reason). Whether this conclusion also applies to political marketing is an open question. To do this we need to look more carefully at autonomous deliberation and intellectual autonomy. Beckman equates the claim that political marketing interferes with autonomous deliberation with the claim that it interferes with intellectual autonomy. In the next two sections I try to drive a wedge between these two claims by considering two papers that critique forms of persuasion that have a lot in common with political and science marketing on the grounds that they infringe with our intellectual autonomy.

\section{Riley on Nudging and Epistemic Injustice}

In his "The Beneficent Nudge Programme and Epistemic Injustice" Evan Riley (2017) argues that the beneficent nudge programme, as defended by Richard Thaler and Cass Sunstein in their book Nudge and several articles (Thaler and Sunstein 2008; 2003; Sunstein 2015a; 2015b), is problematic on both ethical and epistemological grounds. His basic claim is that the programme has the potential to cause a distinctive kind of epistemic injustice. In this section I will briefly outline his argument, before drawing out what I think it shows—and does not showabout autonomous deliberation and intellectual autonomy.

We can start with what nudging is, and how it is related to the science and political marketing strategies I discussed in the previous section. As Thaler and Sunstein define it, a nudge is "any aspect of the choice architecture that alters behavior in a predictable way without forbidding any options" (2008, 6). For example, a doctor who needs to tell a patient about the chances of success of a potentially lifesaving, but risky, operation has a choice to make. They can either say what percentage of patients who have the operation are alive in $\mathrm{x}$ years' time, or they can say what percentage of patients who have it are dead in $\mathrm{x}$ years' time. While these are statistically equivalent, there is evidence that focusing on how many patients live makes it more likely that the patient will opt to have the operation than focusing on how many patients die (McNeil et al. 1982). A doctor who knows this has the power to alter patient behaviour in a predictable way, but they do not force patients to choose one way rather than the other. The crucial aspect of nudging is 
that, while it involves interfering with someone's deliberations and decisionmaking with the aim of making them better off, it avoids any sort of coercion.

Why does Riley think that nudges are? be problematic? As Riley puts it:

[Thaler and Sunstein] do not simply hold that nudging is in some circumstances morally permitted and practically called for. Rather, they favor and would have us foster the broad adoption of the beneficent nudge, to be deployed as a general purpose tool for good, across the institutional milieu of contemporary social life. In a recent defense of implementing this-which I call the beneficent nudge program (BNP) - Sunstein has gone so far as to christen and defend the 'First Law of behaviorally informed regulation: In the face of behavioral market failures, [beneficent] nudges are usually the best response, at least when there is no barm to others' (p. 598). ${ }^{3}$

Riley's target is not nudging per se but the "beneficent nudge programme". The beneficent nudge programme combines two elements. First, nudges should be "deployed as a general purpose tool for good"-for Thaler and Sunstein, this means that they should be deployed to help people make the decisions they would make if they were better at figuring out what was in their long term interest. Second, nudges should be employed widely (cf. Sunstein's First Law).

We can now look at Riley's objection to the beneficent nudge programme. His basic point is that, while nudges don't exactly bypass the "nudgee's" (the person who is nudged) critical faculties, they also don't engage them fully. When someone is nudged, they may be made aware of important new information (in the example above, the patient is made aware of some relevant statistics). They may also engage in rational inference (in the example above, they might compare the survival statistics for the operation with what they know about their chances of survival given the disease they have). But the crucial point is that their reflective critical capacities are not fully engaged. Thus, while being nudged occasionally may not be much of a problem (you will have plenty of opportunities to fully engage your critical capacities), it is a problem if you are systematically (i.e. regularly) nudged. This will prevent you from developing the capacity to "reason critically, energetically and otherwise well" (p. 604). Riley thinks that this may even constitute a form of epistemic injustice:

denying or neglecting to provide people the support, opportunities, or means necessary to develop those capacities [e.g. the capacity to reason critically], or making it relatively more difficult to develop and exercise those capacities, where this lack could be supplied or ameliorated without duly weighty sacrifice or some other comparatively serious consideration, is unjust. In addition, the

\footnotetext{
${ }^{3}$ Riley is quoting from Sunstein (2015b).
} 
character of this general kind of wrong cannot be made fully explicit without reference to the epistemic nature of the victim. Thus, it counts as an epistemic injustice. Call it reflective incapacitational injustice (p. 605).

For my purposes we don't need to worry about the ins and outs of what Riley means by a "reflective incapacitational injustice". All we need is the claim that, while being subject to the occasional nudge may not do much harm, being subjected to a systematic programme of nudging (whether beneficent or not) deprives one of the opportunity to develop the capacity to reason critically.

This completes my overview of Riley's argument. I now want to relate it more directly to the science marketing strategies I discussed in the previous sections, and to autonomous deliberation and intellectual autonomy.

I will start with two preliminaries. First, we can view the science marketing strategies discussed in the previous sections as nudges. If you frame the issue of climate change in a certain way, select a messenger because you think they will be listened to, or engage in prebunking then you are altering the epistemic environment in such a way that it is more likely that a certain outcome is achieved, but without any element of coercion. It is still possible to reject the new framing, to ignore the new messenger, or refuse to be "prebunked".

Second, while Riley focuses on engaging critical faculties and the capacity to think critically rather than autonomous deliberation and intellectual autonomy, these things are clearly closely connected. Roughly speaking, engaging your critical faculties is an essential part of autonomous deliberation, and the capacity to think critically is an essential part of being intellectually autonomous. I will leave it open just how much more there is to autonomous deliberation and intellectual autonomy than this. ${ }^{4}$

The crucial question is whether the science marketing strategies I discussed earlier run into the same problems Riley thinks the beneficent nudge programme runs into. Riley's discussion points to a reason for thinking that science marketing need not run into the same problems. Recall that Riley distinguishes between preventing someone from fully engaging their reflective critical capacities in a particular case and preventing them from developing the capacity to reason critically. In nudging someone you may prevent them from fully engaging their reflective critical capacities at the point at which you nudge them. But clearly this need not prevent them from developing the capacity to reason critically. Riley's point is that over-use of nudging as a strategy has this problematic result, not that every nudge does. Put in terms of autonomous deliberation and intellectual autonomy, Riley's point is

\footnotetext{
${ }^{4}$ On some views (e.g. Zagzebski 2013) they seem to come to almost the same thing.
} 
that interfering with someone's deliberations in a particular case is not the same thing as interfering with their intellectual autonomy. This is because intellectual autonomy is a capacity and preventing someone from manifesting a capacity at a particular point in time is not the same thing as preventing them from having or developing the capacity.

If this is right, then there is some scope to argue that science marketing need not stop anyone from becoming intellectually autonomous. But can anything else be said here? Two things. First, while the proponent of the science marketing methods I have discussed is putting forward a programme, it is a far more limited programme than Thaler and Sunstein's beneficent nudge programme. Thaler and Sunstein envisage using nudges in all areas where humans seem to do a bad job of making choices and decisions that serve what many would regard as their interests. The science marketer proposes nudging who are otherwise unwilling to accept the science on climate change and similar issues to change their minds. To the extent that Riley's objection to the beneficent nudge programme is simply based on how extensive it is, it doesn't carry over to science marketing.

Second, the aims of those who want to (better) market science differ from the aims of commercial (and perhaps political) marketers. This remark by Dan Kahan (a proponent of science marketing) is suggestive:

It would not be a gross simplification to say that science needs better marketing. Unlike commercial advertising, however, the goal of these techniques is not to induce public acceptance of any particular conclusion, but rather to create an environment for the public's open-minded, unbiased consideration of the best available scientific information (2010, 297).

Kahan is saying that the aim of science marketing is to facilitate reasoning critically about issues like climate change. If this is right, then we can make a stronger point. Perhaps surprisingly, it might turn out that the best way to enable people to become intellectually autonomous can sometimes be to infringe on their deliberations about particular issues. Clearly, this isn't going to apply across the board. It is hard to see how commercial marketing makes anyone more intellectually autonomous, and perhaps much the same can be said about political marketing. But this might be because of the aims of commercial and political marketers, rather than because of anything inherent to marketing itself.

\section{Meehan on Nudging and Epistemic Vices}

I have argued that, while Riley may succeed in showing that the beneficent nudge programme infringes on intellectual autonomy, his argument actually points to some reasons for thinking that science marketing need not infringe on intellectual autonomy. In "Epistemic Vices and Epistemic Nudging: A Solution?” Daniella Meehan (2020) makes a similar point to Riley, but in a different way. It will 
therefore be worth seeing whether her paper supports the argument of the previous section. As it will turn out, while Meehan puts her objection to nudging in different terms to Riley, at best she succeeds in establishing the same conclusion.

Where Riley argues that the beneficent nudge programme is problematic on the grounds that it commits a distinctive sort of epistemic injustice, Meehan argues that the programme is, at best, minimally effective in combatting our various epistemic vices and, at worst, leads to the creation of further epistemic vices. To provide some focus we can start with two of her core cases, one of which is fictitious and the other of which is drawn from the real world.

In the fictitious example Harry forms various false beliefs about politics and related matters because he makes extensive use of unreliable news sources and, further, is unwilling to look at what are clearly more reliable sources. Harry, in short, is closed-minded, and perhaps even closed-minded about his closedmindedness. ${ }^{5}$ Meehan asks: what can we do about Harry? We could sit him down and calmly lay out the reasons why he is being epistemically vicious. Or we could try nudging. We could, for example, offer him a discounted subscription to a more reliable paper, leave unbiased news programmes on TV, and so on. These are nudges because, while they are interventions that are intended to improve Harry's epistemic situation, his freedom of choice is not taken away.

For her real-world example, Meehan looks at Michigan's use of the "inconvenience model" for tackling falling rates of child vaccination. The basic idea behind the inconvenience model is to put various barriers in place to securing an exemption from the requirement to vaccinate children before sending them to school and daycare. In Michigan, parents were required to attend educational sessions about vaccines at local public health centres, and to use an official state form to apply for exemptions. This had a demonstrable impact on exemption rates, which went down by 39\% state-wide and by 60\% in the Detroit area (Higgins 2016). Meehan thinks this is a good example of a nudge because, while the intent behind these policies was to produce a particular outcome (i.e. a reduction in the exemption rate), parents were still free to not vaccinate their children.

Meehan argues for two main claims. Her first claim is that, even if nudging is successful in tackling epistemic vices in the short-term, it is ineffective in the longterm. Here is her basic argument ("EN" refers to "epistemic nudging", which as far as I can tell is just nudging):

\footnotetext{
${ }^{5}$ Closed-mindedness is a good example of what Quassim Cassam (2019) calls a "stealthy vice" - a vice that "blocks" its own detection, in that those who have it are unwilling to recognise that they have it because of the very vice in question.
} 
When EN claims to have successfully mitigated a vice, like the examples presented earlier, what has really happened is that EN has merely masked the epistemic vice at hand. EN can only mask epistemic vices as the deep nature of vices remains present. EN does not change the vice in any way, just like the bubble wrap did not change the fragility of the vase, but only masks it, and when EN practices are not employed the vice is still present, just like how the fragility of the vase still remains when the bubble-wrap is removed (p. 253).

So, in Meehan's first example, even if your attempts to get Harry to consult more reliable news sources are successful in the short-term, they are merely masking his closed-mindedness, which will inevitably resurface in the future. More generally, Meehan's thought is that it is easier to change behaviour than to change underlying character traits and, insofar as nudging seems more focused on changing behaviour than underlying character traits, it is easy to see why it would merely mask underlying vices. In her second example, it is a little harder to evaluate her claim because it really depends on why the "inconvenience model" was so successful in Michigan. Did it change anyone's minds, or did it work just because it made avoiding vaccination so inconvenient? If it just made avoiding vaccination very inconvenient, it becomes unclear whether it even qualifies as a nudge. ${ }^{6}$

I think Meehan's first claim is plausible, but for my purposes I don't need to dispute it. Returning to the problem I started with (Anderson's tension), what we need is a way of securing democratic legitimacy for science-based public policy. While tackling the epistemic vices underlying climate change skepticism and other forms of science denialism would be one way of securing this legitimacy, it isn't the only way of doing it. From the standpoint of democratic legitimacy, more shortterm solutions that focus on changing what people are and aren't willing to accept are perfectly viable and perhaps more realistic.

That said, I want to make two points in response to Meehan's argument. The first is that, as Quassim Cassam emphasises in his recent book Vices of the Mind, it can be incredibly difficult to get started with tackling our epistemic vices. If - as Harry is-you are closed-minded, then your closed-mindedness can be a barrier to even recognising that you are closed-minded (see fn. 5). Partly for this reason, it might be best to "start small" and try to change Harry's behaviour before tackling his underlying character traits. This leads to the second point, which is that it is a common idea in the virtue ethics and epistemology literature that acquiring a virtue requires habituation. Part of becoming open-minded is behaving in open-minded ways. While genuine open-mindedness requires more than behaving in an openminded way, it might be argued that behaving in an open-minded way can help you become genuinely open-minded.

${ }^{6}$ See Navin and Largent (2017) for discussion. 
We can now move on to Meehan's second claim, which is that nudging can foster new epistemic vices, such as the vice of epistemic laziness, and more generally can hinder the development of our epistemic capacities. Meehan is getting at a similar idea to Riley:

EN does not merely accidentally fail to engage the critical deliberative faculties of their targets, but purposefully seeks to bypass reflective deliberation entirely. Take the educational tool ... where teachers nudged students towards effective inquiry by teaching incomplete theories to facilitate a better understanding of their complexities. As Riley would note, this form of EN seeks to bypass a genuine open reflective deliberation, meaning for one to nudge successfully in this case (and many others) one must at the time of the nudge, not invite, seek or start any critical reflection or deliberation (p. 254).

While there are some differences between Riley and Meehan, they agree that, in failing to engage the nudgee's critical deliberative faculties, the nudger may well make the nudge unwilling (or even unable) to inquire for themselves and limit their capacity for critical reflection and deliberation. So, much like Riley, Meehan is pointing to the fact that nudging can interfere with our intellectual autonomy. Meehan links her criticism of the nudging programme with some criticisms of Thaler and Sunstein developed by Hausman and Welch (2010). For Hausman and Welch, nudges fail to respect the nudgee's autonomy, and they say that we "should be concerned about the risk that exploiting decision-making foibles will ultimately diminish people's autonomous decision-making capacities (p. 135).

As we saw in the previous section, Riley doesn't think that "one-off' nudges need interfere with anyone's intellectual autonomy. His thought is that subjecting someone to a systematic programme of nudging will make it harder for them to become intellectually autonomous. Meehan seems to be making the stronger claim that nudging itself interferes with intellectual autonomy. But, at least as far as I can see, there is nothing in her argument to support this stronger conclusion. So, while Meehan uses the language of epistemic vices rather than the language of epistemic injustice, her argument shows no more than Riley's does. Relating this back to science marketing, we are left with the same conclusion as in the previous section: because the science marketer is proposing a far more limited programme than Thaler and Sunstein, it is (far) less clear that what they are proposing need infringe on anyone's intellectual autonomy. The point, again, is that preventing someone from deliberating autonomously in a particular case need not prevent them from becoming intellectually autonomous. As I suggested at the end of the previous section, it may help them become more intellectually autonomous.

\section{Conclusion}

Let's take stock. I started with a tension between the demands of responsible public policy making and democratic legitimacy. Responsible public policy making 
in a technologically advanced society should be based on the available scientific evidence. But, to be democratically legitimate, there must be broad acceptance of the policies which are put into place, which seems to require broad acceptance of the science on which the policies are based. The tension arises because there is often not broad (enough) acceptance of the science on which public policy making might be based.

I then did two things. First, I deepened the tension by showing that many of the most effective methods for securing broad acceptance of the science on climate change seem to infringe on our intellectual autonomy. If this appearance is accurate, then they are not themselves democratically legitimate. Second, I made a start at resolving this deeper tension by arguing that, despite appearances, science marketing strategies need not infringe on our intellectual autonomy.

There remain (at least) two open questions. The first is whether I have shown that the science marketing strategies I have discussed can be used to secure the broad acceptance of climate change in a way that is democratically legitimate. You might object that it isn't enough to show that they need not infringe on our intellectual autonomy. They may be democratically illegitimate for other reasons, not least because, if they are going to work, we can't seek any sort of consent before using them. I don't have a particularly firm view on this issue, so I will set it aside.

The second question concerns intellectual autonomy. Throughout I have taken it for granted that intellectual autonomy is important and valuable, and my task has been to show that science marketing need not infringe on it. But you might object that there is something problematic about intellectual autonomy itself. In the literature it is a familiar point that certain conceptions of intellectual autonomy are problematic because they conceive of it in such a way that it is simply unattainable, or in such a way that it isn't clear why we should value it. Take, for instance, a view of intellectual autonomy on which the intellectually autonomous agent is maximally self-reliant. Even setting aside whether a human being can be maximally selfreliant, it seems clear that anyone who strives to be maximally self-reliant is going to miss out on a lot of knowledge (cf. Adam Carter 2017). Given this, it is unclear why we should even want to be maximally self-reliant. But those who criticise conceptions of intellectual autonomy on these grounds typically propose a way of conceiving of it on which it is both (often) attainable and valuable. ${ }^{7}$ It is worth considering whether, even if intellectual autonomy is attainable, it is something that we ought to value quite as much as many of us seem to (cf. the authors I have discussed in this chapter). Intellectual autonomy may be a good thing, but so is having true beliefs, and-especially given the empirical work on human psychology

\footnotetext{
${ }^{7}$ While their accounts of intellectual autonomy differ, Carter (2017), Roberts and Wood (2007) and Zagzebski (2013) all fit this characterisation.
} 
I have discussed in this chapter-it is hard to see why striving for intellectual autonomy should generally be the best (or even a good) way of getting true beliefs. ${ }^{8}$

\section{References}

Adam Carter, J. 2017. "Intellectual Autonomy, Epistemic Dependence and Cognitive Enhancement." Synthese, 1-25.

American Academy of Arts \& Sciences. 2018. "Perceptions of Science in America." http://www.publicfaceofscience.org/.

Anderson, Elizabeth. 2006. "The Epistemology of Democracy." Episteme: A Journal of Social Epistemology 3 (1): 8-22.

- 2011. "Democracy, Public Policy, and Lay Assessments of Scientific Testimony." Episteme 8 (2): 144-64.

Bak, Hee-Je. 2001. "Education and Public Attitudes Toward Science: Implications for the 'Deficit Model' of Education and Support for Science and Technology." Social Science Quarterly 82 (4): 779-95.

Ballew, Matthew T., Anthony Leiserowitz, Connie Roser-Renouf, Seth A. Rosenthal, John E. Kotcher, Jennifer R. Marlon, Erik Lyon, Matthew H. Goldberg, and Edward H. Maibach. 2019. "Climate Change in the American Mind: Data, Tools, and Trends." Environment: Science and Policy for Sustainable Development 61 (3): 4-18.

Beckman, Arthur. 2018. "Political Marketing and Intellectual Autonomy." Journal of Political Philosophy 26 (1): 24-46.

Bolsen, Toby, Thomas J. Leeper, and Matthew A. Shapiro. 2014. "Doing What Others Do: Norms, Science, and Collective Action on Global Warming." American Politics Research 42 (1): 65-89.

Bolsen, Tony, and James N. Druckman. 2015. "Counteracting the Politicization of Science." Journal of Communication 65 (5): 745-69.

Campbell, Troy H., and Aaron C. Kay. 2014. "Solution Aversion: On the Relation between Ideology and Motivated Disbelief." Journal of Personality and Social Psychology 107 (5): 809-24.

Cassam, Quassim. 2019. Vices of the Mind: From the Intellectual to the Political. Oxford: Oxford University Press.

Compton, Josh. 2013. "Inoculation Theory." In The SAGE Handbook of Persuasion: Developments in Theory and Practice, edited by James P. Dillard and Lijiang Shen, 220-36. Thousand Oaks, CA: Sage Publications.

\footnotetext{
${ }^{8}$ Thanks to Jon Matheson and Kirk Lougheed for comments on an earlier version of this chapter.
} 
Cook, John. 2016. "Countering Climate Science Denial and Communicating Scientific Consensus." Oxford Encyclopedia of Climate Change Communication. https://doi.org/10.1093/acrefore/9780190228620.013.314. . 2017. "Understanding and Countering Climate Science Denial." Journal and Proceedings of the Royal Society of New South Wales 150 (465/466): 207-19.

Cook, John, and Stephan Lewandowsky. 2011. The Debunking Handbook. St. Lucia, Australia: University of Queensland. http://sks.to/debunk.

Cook, John, Stephan Lewandowsky, and Ullrich K. H. Ecker. 2017. "Neutralizing Misinformation through Inoculation: Exposing Misleading Argumentation Techniques Reduces Their Influence." PloS One 12 (5): e0175799.

Cook, John, Sander van der Linden, Edward H. Maibach, and Stephan Lewandowsky. 2018. The Consensus Handbook. http://www.climatechangecommunication.org/all/consensus-handbook/.

Cook, John, Naomi Oreskes, Peter T. Doran, William R. L. Anderegg, Bart Verheggen, Edward H. Maibach, J Stuart Carlton, Stephan Lewandowsky, Andrew G. Skuce, and Sarah A. Green. 2016. "Consensus on Consensus: A Synthesis of Consensus Estimates on Human-Caused Global Warming." Environmental Research Letters 11 (4): 048002.

Corner, Adam, Stephan Lewandowsky, Mary Phillips, and Olga Roberts. 2015. The Uncertainty Handbook. Bristol: University of Bristol.

Cvetkovich, George, and Timothy Earle. 1995. Social Trust: Toward a Cosmopolitan Society. Westport, Conn.: Praeger.

Cvetkovich, George, and Ragnar Löfstedt, eds. 1999. Social Trust and the Management of Risk. Abingdon: Earthscan.

Dahlstrom, Michael F. 2014. "Using Narratives and Storytelling to Communicate Science with Nonexpert Audiences." Proceedings of the National Academy of Sciences 111 (Supplement 4): 13614-20.

Dryzek, John S., and Alex Y. Lo. 2015. "Reason and Rhetoric in Climate Communication." Environmental Politics 24 (1): 1-16.

Funk, Cary, and Brian Kennedy. 2019. "How Americans See Climate Change and the Environment in 7 Charts." Pew Research Center. https://www.pewresearch.org/fact-tank/2020/04/21/how-americans-seeclimate-change-and-the-environment-in-7-charts/.

Hamilton, Lawrence C. 2011. "Education, Politics and Opinions about Climate Change Evidence for Interaction Effects." Climatic Change 104 (2): 231-42.

Hamilton, Lawrence C., Joel Hartter, Mary Lemcke-Stampone, David W. Moore, and Thomas G. Safford. 2015. "Tracking Public Beliefs about Anthropogenic Climate Change.” PLoS One 10 (9): e0138208.

Hardisty, David J., Eric J. Johnson, and Elke U. Weber. 2010. "A Dirty Word or a Dirty World? Attribute Framing, Political Affiliation, and Query Theory." Psychological Science 21 (1): 86-92.

Hausman, Daniel M., and Brynn Welch. 2010. "Debate: To Nudge or Not to Nudge." Journal of Political Philosophy 18 (1): 123-36. 
Higgins, Lori. 2016. "More Michigan Parents Willing to Vaccinate Kids." Detroit Free Press, 2016.

https://eu.freep.com/story/news/education/2016/01/28/immunizationwaivers-plummet-40-michigan/79427752/.

Hornsey, Matthew J., Emily A. Harris, Paul G. Bain, and Kelly S. Fielding. 2016. "Meta-Analyses of the Determinants and Outcomes of Belief in Climate Change." Nature Climate Change 6 (6): 622-26.

Ipsos MORI. 2014. "Public Attitudes to Science 2014." https://www.britishscienceassociation.org/public-attitudes-to-sciencesurvey.

Ivanov, Bobi, Jeanetta D Sims, Josh Compton, Claude H. Miller, Kimberly A. Parker, James L. Parker, Kylie J. Harrison, and Joshua M. Averbeck. 2015. "The General Content of Postinoculation Talk: Recalled Issue-Specific Conversations Following Inoculation Treatments." Western Journal of Communication 79 (2): 218-38.

Kahan, Dan. 2010. "Fixing the Communications Failure." Nature 463: 296-97. . 2014. "Making Climate-Science Communication Evidence-Based--All the Way Down." In Culture, Politics and Climate Change, edited by M. Boykoff and D. Crow, 203-20. New York: Routledge.

Kahan, Dan, Hank Jenkins-Smith, and Donald Braman. 2011. "Cultural Cognition of Scientific Consensus.” Journal of Risk Research 14 (2): 147-74.

Kahan, Dan, Hank C. Jenkins-Smith, Tor Tarantola, Carol L. Silva, and Donald Braman. 2015. "Geoengineering and Climate Change Polarization: Testing a Two-Channel Model of Science Communication." Annals of American Academy of Political and Social Science 658: 193-222.

Kitcher, Philip. 2001. Science, Truth, and Democracy. Vol. 112. Oxford University Press.

Lewandowsky, Stephan, Ullrich K. H. Ecker, Colleen M. Seifert, Norbert Schwarz, and John Cook. 2012. "Misinformation and Its Correction: Continued Influence and Successful Debiasing." Psychological Science in the Public Interest 13 (3): 106-31.

Lewandowsky, Stephan, Gilles E. Gignac, and Samuel Vaughan. 2013. “The Pivotal Role of Perceived Scientific Consensus in Acceptance of Science." Nature Climate Change 3 (4): 399-404.

Lewandowsky, Stephan, and Klaus Oberauer. 2016. "Motivated Rejection of Science." Current Directions in Psychological Science 25 (4): 217-22.

Linden, Sander van der, Anthony Leiserowitz, Geoffrey D. Feinberg, and Edward Maibach. 2014. "How to Communicate the Scientific Consensus on Climate Change: Plain Facts, Pie Charts or Metaphors?” Climatic Change 126 (1-2): 255-62.

Linden, Sander van der, Anthony Leiserowitz, Seth Rosenthal, and Edward Maibach. 2017. "Inoculating the Public Against Misinformation about Climate Change.” Global Challenges 1 (2): 1600008. 
MacInnis, Bo, John A. Krosnick, Adina Abeles, Margaret R. Caldwell, Erin Prahler, and Debbie Drake Dunne. 2015. “The American Public's Preference for Preparation for the Possible Effects of Global Warming: Impact of Communication Strategies." Climatic Change 128 (1-2): 17-33.

McNeil, Barbara J., Stephen G. Pauker, Harold C. Sox Jr., and Amos Tversky. 1982. "On the Elicitation of Preferences for Alternative Therapies." The New England Journal of Medicine 306 (21): 1259-62.

Meehan, Daniella. 2020. "Epistemic Vice and Epistemic Nudging: A Solution." In Epistemic Paternalism: Conceptions, Justifications and Implications, edited by Guy Axtell and Amiel Bernal, 247-59. London: Rowman \& Littlefield.

Moser, Susanne C., and Lisa Dilling. 2011. "Communicating Climate Change: Closing the Science-Action Gap." In The Oxford Handbook of Climate Change and Society, edited by John S. Dryzek, Richard B. Norgaard, and David Schlosberg, 161-74. Oxford: Oxford University Press.

Navin, Mark Christopher, and Mark Aaron Largent. 2017. "Improving Nonmedical Vaccine Exemption Policies: Three Case Studies." Public Health Ethics 10 (3): 225-34.

Pfau, Michael. 1995. "Designing Messages for Behavioral Inoculation." In Designing Health Messages: Approaches from Communication Theory and Public Health Practice, edited by Edward H. Maibach and Roxanne L. Parrott, 99-113. Thousand Oaks, CA: Sage Publications.

Pfau, Michael, and Michael Burgoon. 1988. "Inoculation in Political Campaign Communication.” Human Communication Research 15 (1): 91-111.

Riley, Evan. 2017. "The Beneficent Nudge Program and Epistemic Injustice." Ethical Theory and Moral Practice 20 (3): 597-616.

Roberts, Robert C., and W. Jay Wood. 2007. Intellectual Virtues: An Essay in Regulative Epistemology. Oxford: Clarendon Press.

Seifert, Colleen M. 2002. "The Continued Influence of Misinformation in Memory: What Makes a Correction Effective?" In Psychology of Learning and Motivation, 41:265-92. Academic Press.

Sturgis, Patrick, and Nick Allum. 2004. "Science in Society: Re-Evaluating the Deficit Model of Public Attitudes." Public Understanding of Science 13 (1): 5574.

Sunstein, Cass R. 2015a. "Nudging and Choice Architecture: Ethical Considerations." SSRN.

http://papers.ssrn.com/sol3/papers.cfm?abstract_id=2551264. . 2015b. Why Nudge? New Haven: Yale University Press.

Thaler, Richard H., and Cass R. Sunstein. 2003. "Libertarian Paternalism." The American Economic Review 93 (2): 175-79.

- 2008. Nudge: Improving Decisions about Health, Wealth, and Happiness. New Haven: Yale University Press.

Tranter, Bruce, and Kate Booth. 2015. "Scepticism in a Changing Climate: A Cross-National Study." Global Environmental Change 33: 154-64. 
Zagzebski, Linda. 2013. "Intellectual Autonomy.” Philosophical Issues 23 (1): 244-61. 